\title{
Tautomeric Equilibrium of an Asymmetric $\beta$-Diketone in Halogen-Bonded Cocrystals with Perfluorinated Iodobenzenes
}

\author{
Valentina Martinez ${ }^{1,2}$, Nikola Bedeković ${ }^{1}\left(\mathbb{D}\right.$, Vladimir Stilinović ${ }^{1, *(\mathbb{D})}$ and Dominik Cinčić ${ }^{1, * \mathbb{D}}$ \\ 1 Department of Chemistry, Faculty of Science, University of Zagreb, Horvatovac 102A, 10000 Zagreb, Croatia; \\ vmartin@irb.hr (V.M.); nbedekovic@chem.pmf.hr (N.B.) \\ 2 Ruđer Bošković Institute, Bijenička cesta 54, 10000 Zagreb, Croatia \\ * Correspondence: vstilinovic@chem.pmf.hr (V.S.); dominik@chem.pmf.hr (D.C.); Tel.: +385-1-4606-371 (V.S.); \\ +385-1-4606-362 (D.C.)
}

check for updates

Citation: Martinez, V.; Bedeković, N.; Stilinović, V.; Cinčić, D. Tautomeric Equilibrium of an Asymmetric $\beta$-Diketone in Halogen-Bonded Cocrystals with Perfluorinated Iodobenzenes. Crystals 2021, 11, 699. https://doi.org/10.3390/ cryst11060699

Academic Editors: Sergiy Rosokha and Atash V. Gurbanov

Received: 20 May 2021

Accepted: 16 June 2021

Published: 18 June 2021

Publisher's Note: MDPI stays neutral with regard to jurisdictional claims in published maps and institutional affiliations.

Copyright: (c) 2021 by the authors. Licensee MDPI, Basel, Switzerland. This article is an open access article distributed under the terms and conditions of the Creative Commons Attribution (CC BY) license (https:/ / creativecommons.org/licenses/by/ $4.0 /)$.

\begin{abstract}
In order to study the effect of halogen bond on tautomerism in $\beta$-diketones in the solid-state, we have prepared a series of cocrystals derived from an asymmetric $\beta$-diketone, benzoyl-4-pyridoylmethane (b4 pm), as halogen bond acceptor and perfluorinated iodobenzenes: iodopentaflourobenzene (ipfb), 1,2-, 1,3- and 1,4-diiodotetraflorobenzene (12tfib, 13tfib and 14tfib) and 1,3,5-triiodo-2,4,6-trifluorobenzene (135titfb). All five cocrystals are assembled by I $\cdots \mathrm{N}$ halogen bonds involving pyridyl nitrogen and iodoperfluorobenzene iodine resulting in 1:1 (four compounds) or 1:2 (one compound) cocrystal stoichiometry. Tautomer of $\mathbf{b} 4 \mathbf{p m}$ in which hydrogen atom is adjacent to the pyridyl fragment was found to be more stable in vacuo than tautomer with a benzoyl hydroxyl group. This tautomer is also found to be dominant in the majority of crystal structures, somewhat more abundantly in crystal structures of cocrystals in which additional I...O halogen bond with the benzoyl oxygen has been established. Attempts have also been made to prepare an equivalent series of cocrystals using a closely related asymmetric $\beta$-diketone, benzoyl-3-pyridoylmethane (b3 pm); however, all attempts were unsuccessful, which is attributed to more effective crystal packing of $\mathbf{b} \mathbf{3 p m}$ isomer compared to b4pm, which reduced the probability of cocrystal formation.
\end{abstract}

Keywords: pyridyl-diketone; halogen bonding; intramolecular hydrogen bonding; tautomerization

\section{Introduction}

One of the intriguing aspects of the study of halogen bonding, and supramolecular interactions in general, is the interrelationship between different types of interactions (competition, cooperativity, anti-cooperativity, etc.) [1-8]. This is particularly important in crystal engineering and drug design, where the interdependence of different interactions may significantly alter the supramolecular behaviour of molecules in crystals, often leading to unexpected effects [9-14].

One area of interest is the study of the effect of supramolecular interactions on hydrogen transfer through a hydrogen bond. This has been widely studied on systems with intermolecular hydrogen bonding, most commonly between carboxylic acids and nitrogen bases, where the transfer of the hydrogen atom also induces the formation of ions, which in turn can have a considerable effect on the structures and properties of the solids [15-20]. However, when the proton transfer occurs through an intramolecular hydrogen bond, the effect is not a formation of ions but rather a change in the tautomeric form of the molecule.

The effect of supramolecular interaction on tautomeric equilibrium in the solid-state has been studied to some extent for aromatic o-hydroxyimines (Schiff bases), where the intramolecular transfer of the hydrogen atom from the hydroxyl to the imino group leads to the formation of keto-amino tautomer [21]. It has been demonstrated that hydrogen bond with the oxygen atom can greatly facilitate this proton transfer in the solid-state by stabilizing the keto-amino form [22-26]. This has led to the question of whether the halogen bond - an interaction in many ways similar to hydrogen bond [27-30]—can have a similar 
effect on the intramolecular hydrogen transfer and stabilization of the keto-amino tautomer. Unfortunately, despite the research on halogen bonded $o$-hydroxyimine systems performed to date [31-37], the answer to this question remained inconclusive. The possible reason for this is that the stabilizing effect of the halogen bond might be too subtle to noticeably affect proton transfer through the highly asymmetric $\mathrm{O}-\mathrm{H} \cdots \mathrm{N}$ hydrogen bond. If so, a tautomeric system with a more symmetric intramolecular hydrogen bond (and subsequently with a smaller energy difference between the tautomers) might provide a better model for the study of the effect of halogen bond on tautomerism.

Possible alternative systems for the study of this phenomenon are $\beta$-diketones, where also an intramolecular proton transfer leads to a change of tautomeric form. An asymmetric $\beta$-diketone can exist as three distinct tautomers, one diketo and two keto-enole tautomers (Figure 1). The two keto-enole tautomers are generally of similar energies and are transformed one to the other by proton transfer through an intramolecular $\mathrm{O}-\mathrm{H} \cdots \mathrm{O}$ hydrogen bond. The stability of the tautomers has been shown to be affected by the nature of the R1, R2 and R3 substituents [38-43], but also, in solution, by the solvent used, which indicates the effect which the supramolecular surroundings can have on the tautomeric equilibrium of $\beta$-diketones $[44,45]$.<smiles>[R19]C(=O)C([R2])C([R1])=O</smiles>

Figure 1. Keto-enol tautomerization in $\beta$-diketones.

For our study, we have decided to cocrystallise two $\beta$-diketones (benzoyl-3pyridoylmethane (b3pm) and benzoyl-4-pyridoylmethane (b4pm)) with perfluorinated iodobenzenes (pentafluoroiodobenzene (ipfb), 1,2-tetrafluorodiiodobenzene (12tfib), 1,4-tetrafluorodiiodobenzene (14tfib), 1,3-tetrafluorodiiodobenzene (13tfib) and 1,3,5trifluorotriiodobenzene (135tfib)) [46-48] as halogen bond donors (Figure 2). The $\beta$-diketones were selected so that they are asymmetric (allowing tor two distinct keto-enol tautomers), with one of the substituents being a pyridine ring, since the introduction of pyridine nitrogen as a superior halogen bond acceptor (949 structures deposited in CSD with halogen $\cdots$ pyridine contacts) [46-50] should increase the probability of obtaining halogenbonded cocrystals. The halogen-bonded cocrystals of 14tfib with symmetric bis(pyridyl) $\beta$-diketones [50], as well as their transition metal complexes [51], have already been reported, and with very few exceptions, halogen bond was found to be formed exclusively with the pyridine nitrogen. However, using $\beta$-diketones with only a single pyridine nitrogen per molecule should enable the formation of halogen bonds both with the pyridine nitrogen and with the keto-enol oxygen atoms (strategy similar to the one employed in the study of $o$-hydroxyimine systems $[33,35])$, the latter being crucial for the determination of the effect of halogen bond (if any) on the positioning of the hydrogen atom within the $\mathrm{O}-\mathrm{H} \cdots \mathrm{O}$ hydrogen bond, and thus on possible stabilization of a given keto-enol tautomer. To compare the relative strength of potential acceptor atoms in the diketone molecules, we have calculated molecular electrostatic potentials (MEPs) on nitrogen and both oxygen atoms, as well as their binding energies to the ipfb iodine atom. Such a combined experimental and computational approach should enable us to detect whether a halogen bond with the $\beta$-diketone oxygen atom has a measurable effect on the tautomeric equilibrium in the solid-state. 


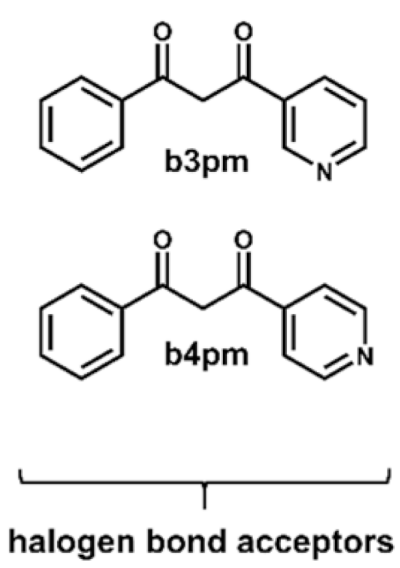

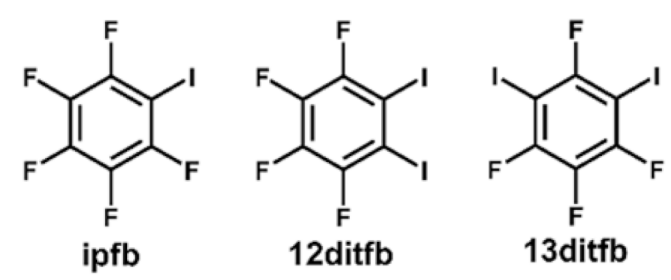

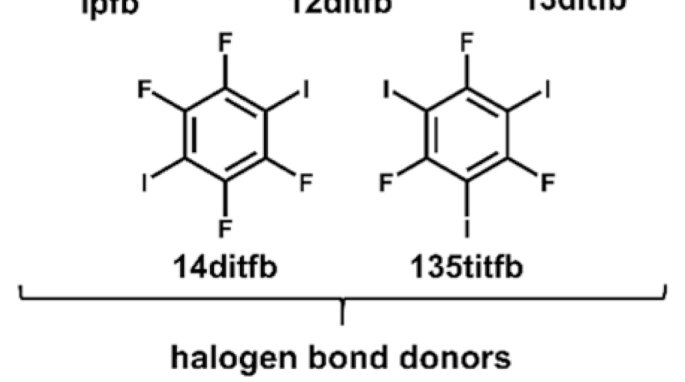

Figure 2. Halogen bond donors and acceptors used in study.

\section{Materials and Methods}

Methyl nicotinate (Sigma-Aldrich Chemie GmbH, Taufkirchen, Germany), methyl isonicotinate (Sigma-Aldrich Chemie $\mathrm{GmbH}$, Taufkirchen, Germany), acetophenone (SigmaAldrich Chemie GmbH, Taufkirchen, Germany), sodium amide (Sigma-Aldrich Chemie $\mathrm{GmbH}$, Taufkirchen, Germany), benzene (Sigma-Aldrich Chemie GmbH, Taufkirchen, Germany), ethanol (Sigma-Aldrich Chemie GmbH, Taufkirchen, Germany), glacial acetic acid (Sigma-Aldrich Chemie GmbH, Taufkirchen, Germany), acetone (Sigma-Aldrich Chemie GmbH, Taufkirchen, Germany) and halogen bond donors ipfb, 12tfib, 13tfib, 14tfib (Manchester Organics Ltd., Cheshire, UK) and 135tfib (Apollo Scientific Ltd., Cheshire, UK) were used without additional purification.

\subsection{Synthesis of Pyridyl Diketones}

Benzoyl-3-pyridoylmethane (b3pm) and benzoyl-4-pyridoylmethane (b4pm) were prepared by the following procedure: sodium amide $(1.44 \mathrm{~g})$ was dispersed in $50.0 \mathrm{~mL}$ of benzene, and a benzene solution of methyl nicotinate or methyl isonicotinate $(40 \mathrm{mmol}$ in $5 \mathrm{~mL}$ of benzene) was added to the mixture. Solution of acetophenone $(20 \mathrm{mmol})$ in benzene $(5 \mathrm{~mL})$ was added dropwise to the formed suspension, and the reaction mixture was stirred at $85{ }^{\circ} \mathrm{C}$ for $7 \mathrm{~h}$ until the brown-yellow product precipitated. The precipitate was filtered off and washed with $5 \%$ acetic acid. The crude products were recrystallised from ethanol $(95 \%)$.

\subsection{Synthesis of the Cocrystals}

In order to examine the ability of the prepared diketones to form cocrystals with halogen bond donors (ipfb, 12tfib, 13tfib, 14tfib and 135tfib), mixtures (100.0 mg) of a diketone and a donor in 1:1 and 1:2 stoichiometric ratios were ground with the addition of small amounts of ethanol $(30 \mu \mathrm{L})$. The obtained powders were then characterized by powder X-ray diffraction to test whether a new phase had formed (comparisons of the measured and calculated powder diffraction patterns for obtained cocrystals are shown in Figures S7-S10 in SI). The grinding experiments were conducted in a Retsch MM200 ball mill (Retsch, Haan, Germany) using $10 \mathrm{~mL}$ stainless steel jars and two stainless steel balls ( $7 \mathrm{~mm}$ in diameter) for $30 \mathrm{~min}$, under normal laboratory conditions (40-60\% relative humidity and temperature ca. $25^{\circ} \mathrm{C}$ ).

Single crystals of cocrystals that were obtained in the mechanochemical experiments were prepared by crystallisation from solution. Corresponding halogen bond donor and b4pm were dissolved in $3 \mathrm{~mL}$ of hot acetone-ethanol mixture (2:1), whereupon solutions were left to cool and evaporate. Crystals suitable for single-crystal X-ray diffraction experiments appeared in three to five days. 


\subsection{X-ray Diffraction Measurements}

Single crystal X-ray diffraction experiments were performed using an Oxford Diffraction Xcalibur Kappa CCD X-ray diffractometer (Oxford Diffraction Ltd., Abingdon, UK) with graphite-monochromated $\operatorname{MoK}_{\alpha}(\lambda=0.71073 \AA)$ radiation. The data sets were collected using the $\omega$-scan mode over the $2 \theta$-range up to $54^{\circ}$. Programs CrysAlis CCD and CrysAlis RED were employed for data collection, cell refinement, and data reduction $[52,53]$. The structures were solved by direct methods and refined using the SHELXS (Version 2013, Göttingen, Germany) and SHELXL (Version 2013, Göttingen, Germany) programs, respectively $[54,55]$. The structural refinement was performed on $F^{2}$ using all data. The hydrogen atoms not involved in the intramolecular hydrogen bond were placed on calculated positions and treated as riding on their parent atoms $(\mathrm{C}-\mathrm{H}=0.93 \AA$ and $\left.U_{\text {iso }}(\mathrm{H})=1.2 U_{\mathrm{eq}}(\mathrm{C})\right)$. In cases where it was possible, the hydrogen atoms of the diketo group in $\mathbf{b} 3 \mathbf{m p}$ and $\mathbf{b} 4 \mathbf{p m}$ were located from electron difference map, while in the case of (b4 pm)(13tfib), they were placed on the calculated positions, the hydroxyl oxygen being identified on the basis of the difference between the two $\mathrm{C}-\mathrm{O}$ bond lengths in the molecule. All calculations were performed using the WinGX crystallographic suite of programs [56]. The figures were prepared using Mercury (Version 4.3.1., CCDC, Cambridge, UK) [57].

Powder X-ray diffraction (PXRD) experiments on the samples were performed on a PHILIPS PW 1840 X-ray diffractometer (Philips Analytical, Almelo, The Netherlands) with $\mathrm{CuK}_{\alpha} 1(1.54056 \AA)$ radiation at $40 \mathrm{~mA}$ and $40 \mathrm{kV}$. The scattered intensities were measured with a scintillation counter. The angular range was from 5 to $45^{\circ}(2 \theta)$ with a continuous step size of $0.02^{\circ}$ and a measuring time of $0.5 \mathrm{~s}$ per step. Data collection was performed using the program package Philips X'Pert (Version 1.3e, Philips Analytical, Almelo, The Netherlands) [58-60] and analysed in the X'Pert HighScore Plus (Version 2.2, Malvern Panalytical, Malvern Worcestershire, UK) [61].

\subsection{Thermal Analysis}

Differential scanning calorimetry (DSC) measurements were performed on a MettlerToledo DSC823e module (Mettler Toledo, Greifensee, Switzerland) in sealed aluminium pans $(40 \mu \mathrm{L})$ with three pinholes in the lid, heated in a stream of nitrogen $\left(150 \mathrm{~mL} \mathrm{~min}^{-1}\right)$ at a heating rate of $10^{\circ} \mathrm{C} \mathrm{min}^{-1}$.

Thermogravimetric measurements (TG) were performed on a Metler-Toledo TGA/SDTA 851e module (Mettler Toledo, Greifensee, Switzerland). Samples were placed in sealed $40 \mu \mathrm{L}$ aluminium pans with three pinholes and heated from 25 to $500{ }^{\circ} \mathrm{C}$, at a rate of

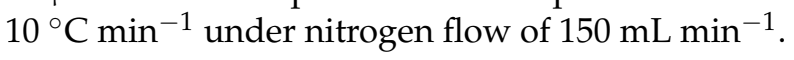

Data collection and analysis were performed using the program package STARe Software (Version 15.00, Mettler Toledo, Greifensee, Switzerland) [62].

\subsection{Computations}

All calculations were performed using Gaussian (Version 09, Revision A.02, Gaussian Inc., Wallingford, UK) software package [63]. Geometry optimizations were performed using M06-2X/dgdzvp [64-66] level of theory with an ultrafine integration grid (99 radial shells and 590 points per shell). This method was shown to reproduce experimental halogen bond energies in the gas phase with good accuracy, which are comparable or even more accurate than energies obtained by using larger triple-zeta basis sets [67]. Optimization of the transition state structure of b4pm was performed using the PM6 semiempirical method [68], after which the obtained transition state was optimized using M06-2X/6$31 \mathrm{~g}+(\mathrm{d}, \mathrm{p})[69]$ and M06-2X/dgdzvp level of theory. Harmonic frequency calculations were performed on the optimized geometries (both coformers and transition state) to ensure the success of each geometry optimization. The figures were prepared using GaussView (Version 5.0.8., Gaussian Inc., Wallingford, UK) [70]. 


\section{Results and Discussion}

As was described in a study performed by Dudek et al. [71], both $\mathbf{b 3} \mathbf{p m}$ and $\mathbf{b} 4 \mathbf{p m}$ in the solid-state exist in keto-enol form, with a strong intramolecular resonance assisted $\mathrm{O}-\mathrm{H} \cdots \mathrm{O}$ hydrogen bond formed between the two oxygen atoms. In both cases, the hydrogen atom is placed closer to the pyridyl oxygen atom, indicating that this keto-enol form is more stable. To test this, we have optimized structures of $\mathbf{b} 3 \mathbf{p m}$ and $\mathbf{b} 4 \mathbf{p m}$ in vacuo. Since the pyridine ring in $\mathbf{b} 3 \mathbf{p m}$ can be oriented in a way that the nitrogen atom is positioned on the same side of the molecule (syn-b3pm) or the opposite side (anti-b3pm), with respect to the diketo group, the computations were performed for both conformers. Of the two conformers of $\mathbf{b} 3 \mathbf{p m}$, the anti-b3pm was found to be more stable (by ca $5 \mathrm{~kJ} \mathrm{~mol}^{-1}$ ), while in both cases, the minimum of the potential energy corresponded to a tautomer with the hydrogen atom bonded to the benzoyl, rather than the pyridyl oxygen, which is found in the crystal structure of $\mathbf{b} 3 \mathbf{p m}$ (Figure S1 in SI). Furthermore, in the case of b4pm, the minimum of the potential energy corresponded to a tautomer with the hydrogen atom bonded to the pyridyl fragment, which is also found in the crystal structure of the $\mathbf{b} 4 \mathbf{p m}$ cocrystals. Indeed, Dudek et al. [71] have also included benzoyl-2-pyridoylmethane in their study, finding the hydrogen atom adjacent to the benzoyl oxygen in the crystal structure and explaining the difference in the tautomeric forms of diketones through different supramolecular interactions in the corresponding crystals.

\subsection{Preparation of the Cocrystals}

Five cocrystals of $\mathbf{b} 4 \mathbf{p m}$ were successfully prepared, both by grinding and crystallisation from solution, one with each of the used halogen bond donors (Table 1, Tables S1 and S2 and Figures S2-S11 in SI). The majority of the cocrystals are of the 1:1 stoichiometry with one exception, $(\mathbf{b} 4 \mathbf{p m})_{2}(\mathbf{1 4} \mathbf{t f i b})$. Melting points of $\mathbf{b} 4 \mathbf{p m}$ cocrystals were found to be in the range between 80 and $108{ }^{\circ} \mathrm{C}$ (Figures S14-S23 in SI), in all five cases lower than the melting point of the pure diketone $\left(115^{\circ} \mathrm{C}\right)$.

Table 1. The results of cocrystal synthesis by grinding and crystallisation from a solution of diketones and used halogen bond donors with melting points and enthalpies of fusion of the prepared cocrystals.

\begin{tabular}{|c|c|c|c|}
\hline Halogen Bond Donor & b4pm & $t_{\mathrm{m}} /{ }^{\circ} \mathrm{C}$ & $\Delta_{\text {fus }} H / \mathrm{kJ} \mathrm{mol}^{-1}$ \\
\hline ipfb & $(\mathrm{b} 4 \mathrm{pm})(\mathrm{ipfb})$ & 80.4 & 20.3 \\
\hline 12tfib & $($ b4pm)(12tfib) & 86.3 & 21.6 \\
\hline 13tfib & $(\mathrm{b} 4 \mathrm{pm})(13$ tfib) & 99.8 & 26.9 \\
\hline 14tfib & $(\mathrm{b} 4 \mathrm{pm})_{2}(14 \mathrm{tfib})$ & 101.5 & 26.7 \\
\hline 135tfib & $(\mathrm{b} 4 \mathrm{pm})(135 \mathrm{tfib})$ & 108.6 & 37.5 \\
\hline
\end{tabular}

Surprisingly, every attempt to prepare cocrystals of $\mathbf{b} 3 \mathbf{p m}$ and any of the selected five donors either by grinding or crystallisation from a solution was unsuccessful. This would seem to indicate that $\mathbf{b} 3 \mathbf{p m}$ is a weaker halogen bond acceptor than $\mathbf{b} 4 \mathbf{p m}$. The quantum-chemical calculations of the molecular electrostatic potential $(M E P)$ of $\mathbf{b} 3 \mathbf{p m}$ and b4pm have shown that the $M E P_{\min }$ values on the pyridyl nitrogen in the two isomers are very close; the $M E P_{\min }$ value on the pyridine nitrogen in the $\mathbf{b} 4 \mathbf{p m}$ is ca. $2 \mathrm{~kJ} \mathrm{~mol}^{-1} \mathrm{e}^{-1}$ more negative than the corresponding $M E P_{\min }$ value in the stable syn-b3pm coformer (Figure 3).

This was also supported by the calculated halogen bond energies for binding of $\mathbf{i p f b}$ to the nitrogen atoms of $\mathbf{b} 3 \mathbf{p m}$ and $\mathbf{b} \mathbf{4} \mathbf{p m}$ molecules, which have shown that there is no significant difference in halogen bond energies $\left(27.1 \mathrm{~kJ} \mathrm{~mol}^{-1}\right.$ for anti-b3pm and ca $27.9 \mathrm{~kJ} \mathrm{~mol}^{-1}$ for $\left.\mathbf{b} 4 \mathbf{p m}\right)$. According to small differences in calculated MEP values and binding energies in vacuo, nitrogen atoms in $\mathbf{b} 3 \mathbf{p m}$ and $\mathbf{b 4} \mathbf{p m}$ are expected to have an approximately equal tendency for halogen bonding with perfluorinated halobenzenes. One should keep in mind, however, that the total energy change upon cocrystallisation is not dependant solely on the (possible) formation of a halogen bond but also on the differences 
in total lattice energies of the pure coformers and the cocrystal. The probable reason that $\mathbf{b} 3 \mathbf{p m}$ has failed to produce a single cocrystal with any of the donors (as opposed to b4pm, which has formed cocrystals with all five) is particularly favourable crystal packing (i.e., high lattice energy) of pure $\mathbf{b} 3 \mathbf{p m}$. This does seem to be in line with melting points of two diketones: melting point of $\mathbf{b} 3 \mathbf{p m}\left(t_{\mathrm{m}}=127.2^{\circ} \mathrm{C}\right)$ is ca $12^{\circ} \mathrm{C}$ higher than the one of the $\mathbf{b} 4 \mathbf{p m}\left(t_{\mathrm{m}}=115.0^{\circ} \mathrm{C}\right.$; Figures S12 and S13 in SI), which indicates that $\mathbf{b} 3 \mathbf{p m}$ forms a crystal with higher lattice energy than $\mathbf{b} 4 \mathbf{p m}$, possibly accounting its reluctance in forming cocrystals with any of the halogen bond donors covered by this study.
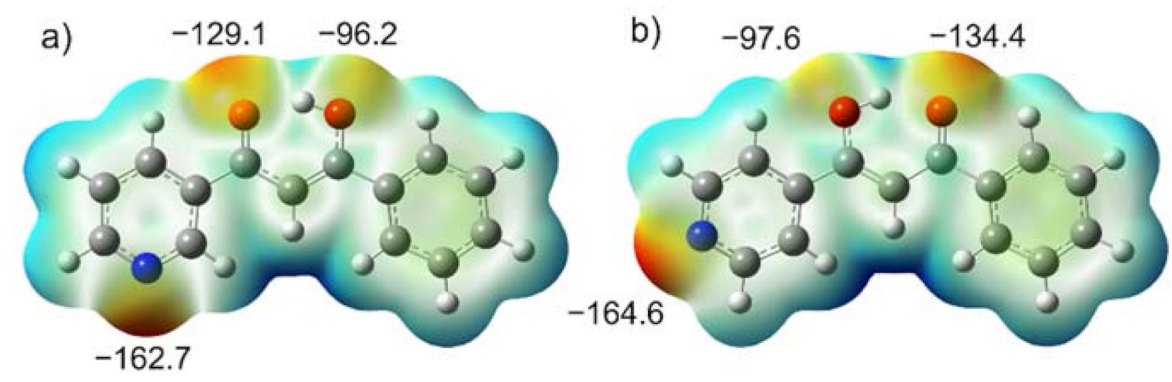

Figure 3. Molecular electrostatic potential mapped on the total electron density surface $\left(0.002 \mathrm{e} \mathrm{A}^{-3}\right)$ of (a) anti-b3pm, (b) b4pm. All values are in $\mathrm{kJ} \mathrm{mol}^{-1} \mathrm{e}^{-1}$.

\subsection{Crystal Structures of Halogen-Bonded Cocrystals}

Considering the calculated molecular electrostatic potentials $(M E P)$ of the prospective acceptor atoms in the $\mathbf{b} \mathbf{4} \mathbf{p m}$ molecule, a nitrogen atom of the pyridoyl moiety is undoubtedly the best acceptor site for halogen bonding (the lowest $M E P_{\min }$ value), which is followed by carbonyl oxygen and lastly, the hydroxyl group of the diketo group (Figure 3, Figures S27-S29). Furthermore, the binding energies of the certain acceptor site in $\mathbf{b 4 p m}$ to ipfb decrease in series I $\cdots \mathrm{N}>\mathrm{I} \cdots \mathrm{O}>\mathrm{I} \cdots \mathrm{OH}$ (Table 2) which is in good accordance with obtained crystal structures in which $\mathrm{I} \cdots \mathrm{N}$ contact is predominantly formed and followed by $\mathrm{I} \cdots \mathrm{O}$ contact. This is well reflected in the obtained crystal structures; the expected halogen bond $\mathrm{I} \cdots \mathrm{N}$ was observed in all prepared compounds, a halogen bond with a carbonyl oxygen atom was also achieved in (b4pm)(12tfib) and (b4pm)(13tfib), while in no structures, the hydroxyl oxygen atom was found to act as a halogen bond acceptor.

Table 2. Binding energies of the ipfb molecule to the different acceptor atoms of $\mathbf{b} 4 \mathbf{p m}$.

\begin{tabular}{|c|c|}
\hline Complex & $E_{\text {bind }} / \mathrm{kJ} \mathrm{mol}^{-1}$ \\
\hline$(\mathrm{b} 4 \mathrm{pm})(\mathrm{ipfb}) \_\mathrm{N}$ & -27.9 \\
\hline$($ b4pm)(ipfb)_O & -23.6 \\
\hline$($ b4pm)(ipfb)_OH & -19.1 \\
\hline
\end{tabular}

The crystallisation of the halogen bond donor $\mathbf{1 2 t f i b}$ with $\mathbf{b} 4 \mathbf{p m}$ yielded a solid-state complex with a 1:1 stoichiometric ratio (Figure 4). In this cocrystal, only one iodine

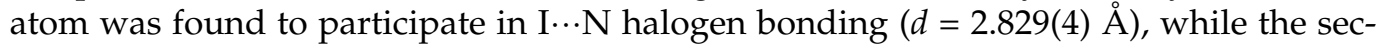
ond one formed an $\mathrm{I} \cdots \mathrm{O}$ halogen bond with the benzoyl oxygen atom of another $\mathbf{b} 4 \mathbf{p m}$ molecule $(d=3.048(3) \AA)$. Such binding resulted in the formation of centrosymmetric $(\mathbf{b} 4 \mathbf{p m})_{2}(\mathbf{1 2 t f i b})_{2}$ tetramers (Figure 4$)$, which are further interconnected into a 3D structure by $\mathrm{C}-\mathrm{H} \cdots \mathrm{F}$ interactions.

Cocrystal obtained from 13tfib and $\mathbf{b} 4 \mathbf{p m}$ was also found to be of 1:1 stoichiometry. The asymmetric unit consisted of three symmetrically independent 13tfib molecules, all of which participated in I $\cdots \mathrm{N}$ halogen bonds, each with one symmetrically independent acceptor molecule (Figure 5). Of these, only one 13tfib formed also an I $\cdots$ O halogen bond (again with a benzoyl oxygen atom; $\left.d(\mathrm{I} 1 \cdots \mathrm{O} 6)=3.025(5) \AA, \angle(\mathrm{I} 1 \cdots \mathrm{O} 6)=167.3(2)^{\circ}\right)$, while the iodine atoms of the other two symmetrically independent 13 tfib molecule participated in I...F contacts with neighbouring donor molecules $\left(d(\mathrm{I} \cdots \mathrm{F} 3)=3.109(3) \AA, \angle(\mathrm{I} 5 \cdots \mathrm{F} 3)=165.4(2)^{\circ}\right.$; 
$\left.d(\mathrm{I} 3 \cdots \mathrm{F} 1)=3.565(3) \AA ; \angle(\mathrm{I} 3 \cdots \mathrm{F} 1)=166.5(1)^{\circ}\right)$. The resulting supramolecular hexamers are interconnected into $2 \mathrm{D}$ sheets by weak $\mathrm{C}-\mathrm{H} \cdots \mathrm{O}$ and $\mathrm{C}-\mathrm{H} \cdots \mathrm{F}$ interactions.

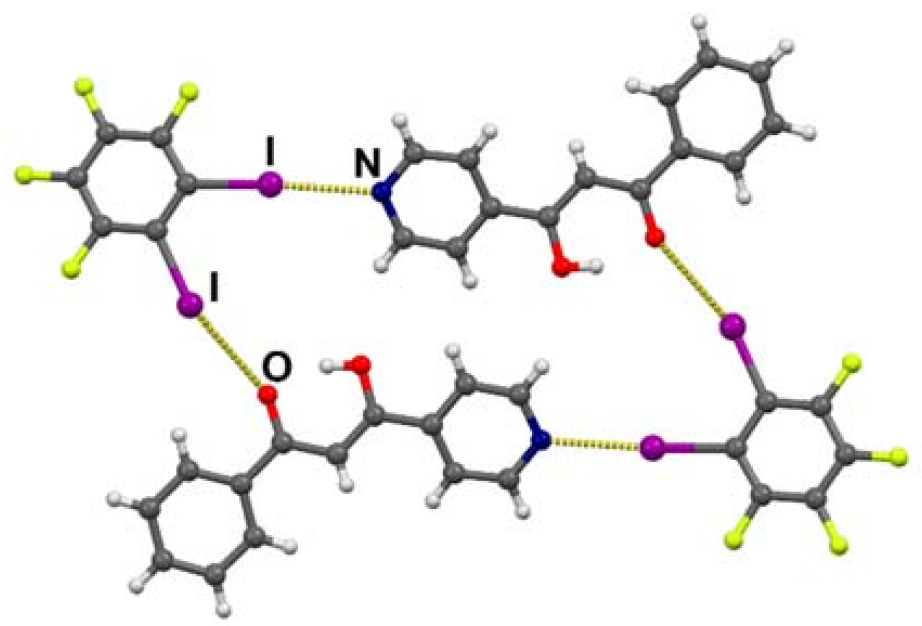

Figure 4. Centrosymmetric dimer formed through $\mathrm{I} \cdots \mathrm{O}$ and $\mathrm{I} \cdots \mathrm{N}$ halogen bonds in (b4pm)(12tfib). Hydroxyl hydrogen atoms were found from the electron difference map.
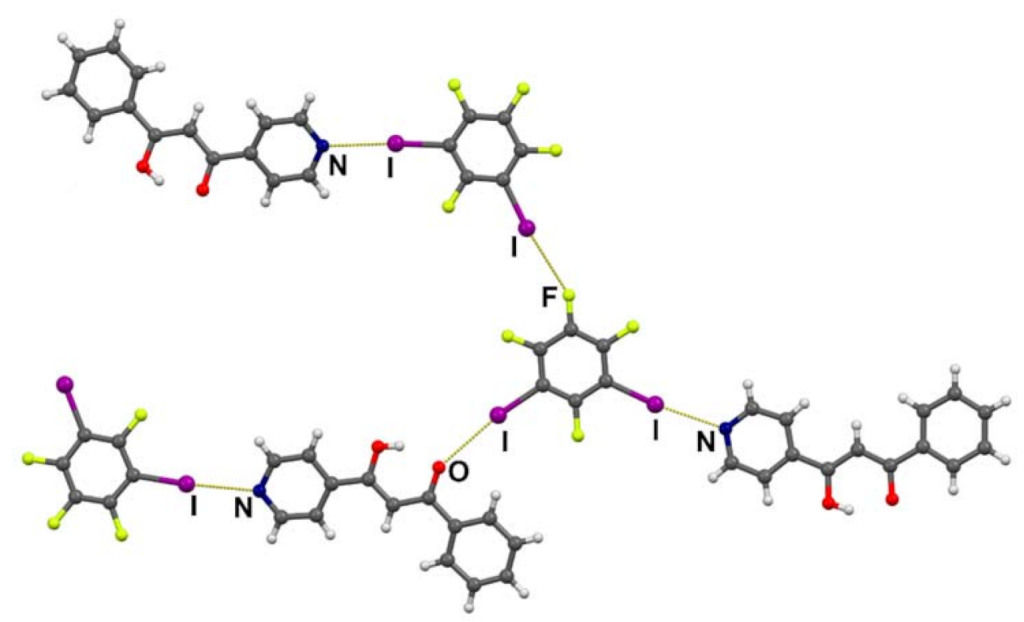

Figure 5. Supramolecular hexamer interconnected by $\mathrm{I} \cdots \mathrm{N}, \mathrm{I} \cdots \mathrm{O}, \mathrm{I} \cdots \mathrm{F}$ and $\mathrm{I} \cdots \mathrm{I}$ halogen bonds in (b4pm)(13tfib). Hydroxyl hydrogen atoms were placed on calculated positions with respect to the lengths of $\mathrm{C}-\mathrm{O}$ bonds.

The combination of $\mathbf{b} 4 \mathbf{p m}$ with the ditopic halogen bond donor 14tfib has resulted in the formation of the halogen bonded cocrystal of 2:1 stoichiometry, (b4pm) 2 (14tfib). Its crystal structure comprises discrete (b4pm) $)_{2}(\mathbf{1 4 t f i b})$ molecular complexes (Figure 6) in which the 14tfib bridges between two $\mathbf{b 4 p m}$ molecules with both iodine atoms of the donor molecule involved in equivalent $\mathrm{I} \cdots \mathrm{N}$ halogen bonds $(d=2.871(5) \AA$, r.s. $=18.7 \%$; $\left.\varphi(\mathrm{I} \cdots \mathrm{N})=172.7(2)^{\circ}\right)$ related by a crystallographic inversion centre. The b4pm molecule in the (b4 pm $)_{2}$ (14tfib) molecular complex is not planar, as evidenced by the value of the dihedral angle between the mean plane of the pyridine ring and the residue of the $\mathbf{b} 4 \mathbf{p m}$ molecule $\left(\psi=12.1(5)^{\circ}\right)$. Uniquely in this structure, the $\mathbf{b} 4 \mathbf{p m}$ molecules are packed in a way that the enolic hydrogen atom participates not only in the intramolecular hydrogen bond but also in intermolecular $\mathrm{O}-\mathrm{H} \cdots \mathrm{O}$ hydrogen bonds, forming a $R_{2}^{2}(12)$ motive, through which the molecular complexes aggregate into chains, which, in turn, form sheets by an interconnection through $\mathrm{C}-\mathrm{H} \cdots \mathrm{F}$ interactions. Due to the established hydrogen-bonded chains, $(\mathbf{b} 4 \mathbf{p m})_{2}(\mathbf{1 4 t f i b})$ have the highest melting point $\left(t_{\mathrm{m}}=109^{\circ} \mathrm{C}\right)$ and enthalpy of fusion $\left(\Delta_{\text {fus }} H=37.5 \mathrm{~kJ} \mathrm{~mol}^{-1}\right)$ of all cocrystals obtained. 


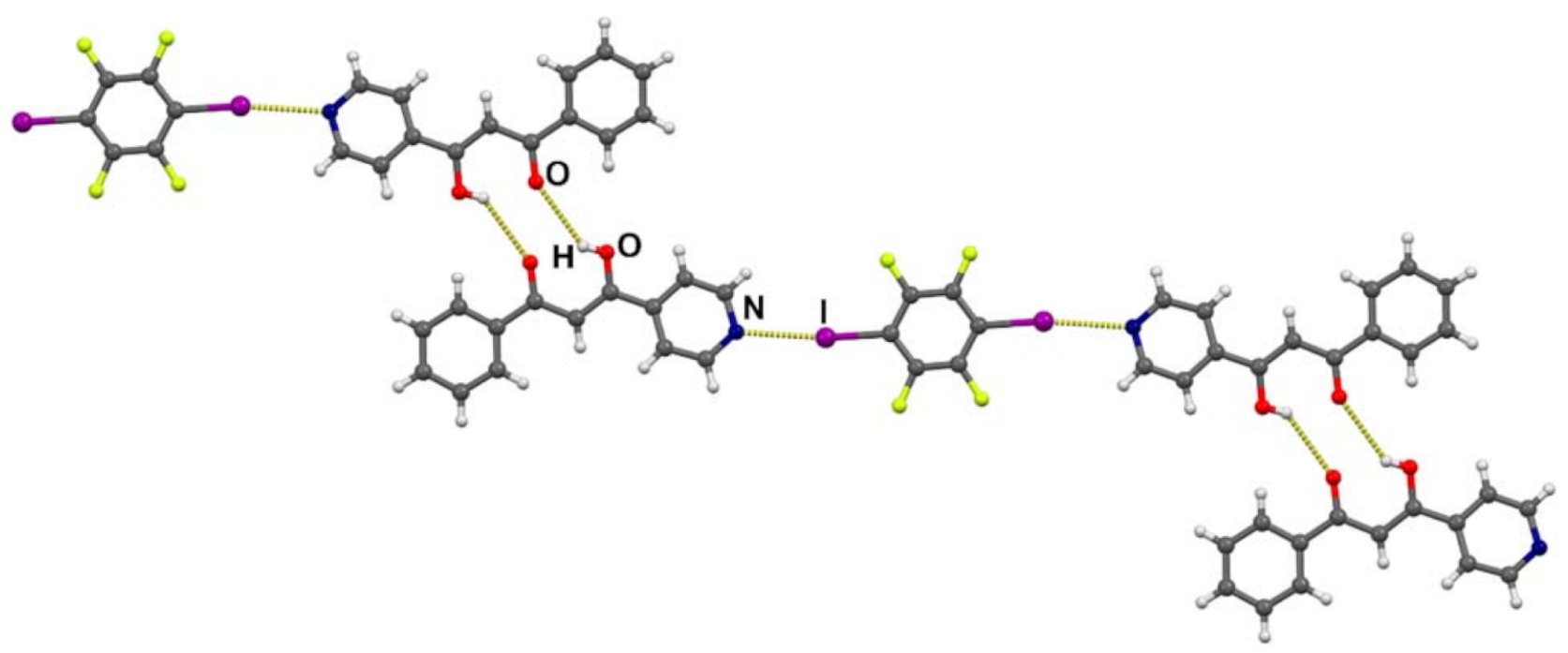

Figure 6. Halogen bonded molecular complex in (b4pm) $)_{2}$ (14tfib). Interconnected into chains through $\mathrm{O}-\mathrm{H} \cdots \mathrm{O}$ hydrogen bonds. Hydroxyl hydrogen atoms were found from the electron difference map.

The monotopic halogen bond donor ipfb also formed a cocrystal with $\mathbf{b} 4 \mathbf{p m}$ of the 1:1 stoichiometry (b4pm)(ipfb) (Figure 7). The I $\cdots \mathrm{N}$ halogen bond in this cocrystal was found to be the shortest and most linear in the entire series of compounds $(d=2.785(4) \AA$; r.s. $\left.=21.1 \% ; \varphi(\mathrm{C}-\mathrm{I} \cdots \mathrm{N})=179.5(2)^{\circ}\right)$. The $(\mathbf{b} 4 \mathbf{p m})(\mathbf{i p f b})$ binary molecular complex is almost planar, with the torsion angle defined by atoms $\psi(\mathrm{C}-\mathrm{N} \cdots(\mathrm{I}) \mathrm{C}-\mathrm{C})$ of only $7.2(5)^{\circ}$. The crystal structure consists of $\mathrm{I} \cdots \mathrm{N}$ halogen bonded complexes connected by $\mathrm{C}-\mathrm{H} \cdots \mathrm{F}$ contacts and $\pi$-stacking into a 3D structure. The weakness of the interactions interconnecting the halogen bonded complexes is also reflected in the melting point and fusion enthalpy of $(\mathbf{b} 4 \mathbf{p m})(\mathbf{i p f b})$, which are the lowest within this series of compounds $\left(t_{\mathrm{m}}=80^{\circ} \mathrm{C}\right.$, $\Delta_{\text {fus }} H=20.3 \mathrm{~kJ} \mathrm{~mol}^{-1}$ ).

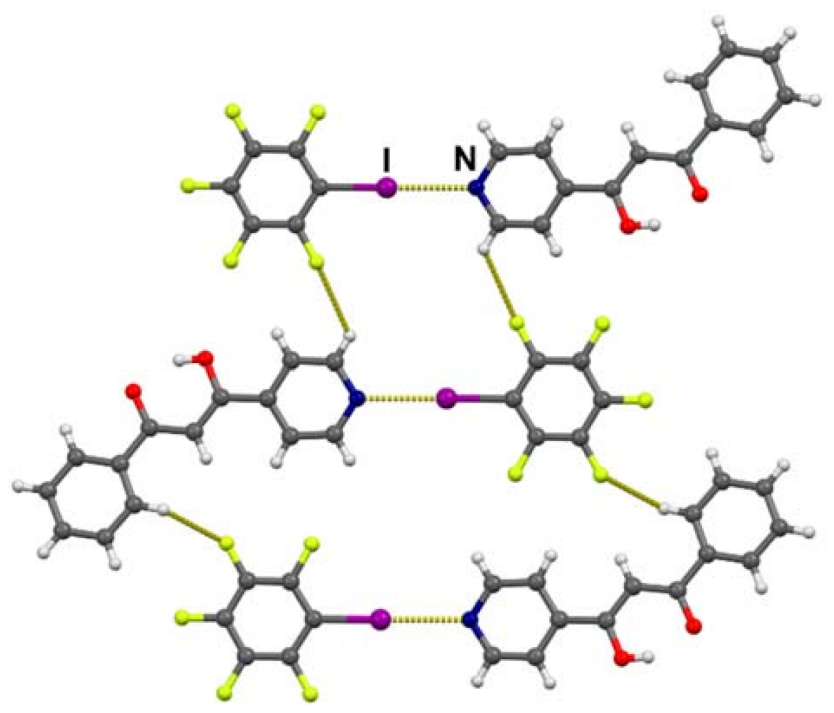

Figure 7. Halogen bonded molecular complexes in (b4pm)(ipfb) interconnected by C-H $\cdots$ F hydrogen bonds into chains. Hydroxyl hydrogen atoms were found from electron difference map.

Cocrystallisation of $\mathbf{b} 4 \mathbf{p m}$ with the tritopic halogen bond donor $\mathbf{1 3 5 t f t i b}$ again yielded a 1:1 cocrystal (Figure 8). The donor molecule has three potential halogen bond donor atoms, which play different roles in the formation of the 3D structure of the obtained cocrystal. One of the iodine atoms participates in halogen bonding with the pyridine nitrogen of the acceptor molecule $\left(d(\mathrm{I} \cdots \mathrm{N})=2.865(7) \AA ; r . s .=18.8 \% ; \varphi(\mathrm{C}-\mathrm{I} \cdots \mathrm{N})=175.2(2)^{\circ}\right)$, thus forming 
a (135tftib)(b4pm) bimolecular complex. The complexes are further interconnected into

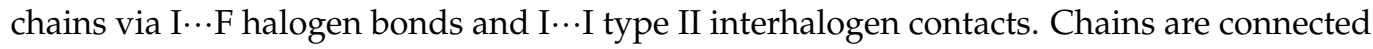
into a 3D structure by $\pi$-stacking.

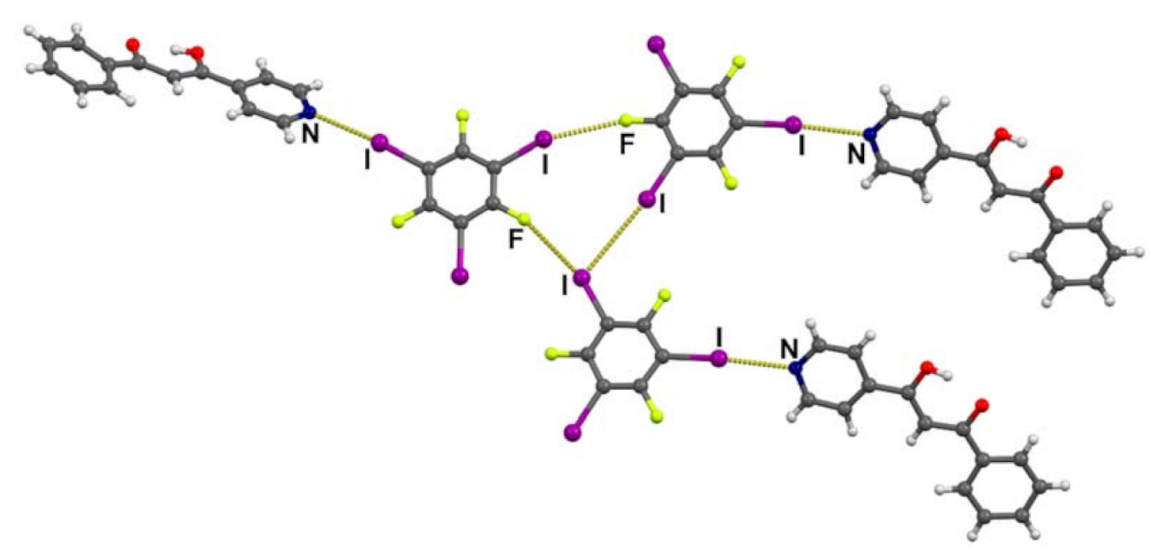

Figure 8. A fragment of a halogen bonded chain of $(\mathbf{b} 4 \mathbf{p m})(\mathbf{1 3 5 t f i b})$ molecular complexes in the crystal structure of $(\mathbf{b} 4 \mathbf{p m})(\mathbf{1 3 5 t f i b})$. Hydroxyl hydrogen atoms were located from the electron difference map.

\subsection{Tautomerism}

It was stated above that $\mathbf{b} 4 \mathbf{p m}$ can exist in two keto-enol tautomer forms: one with hydrogen adjacent to benzyl group (form I) and another with hydrogen on pyridyl fragment (form II). The results of QM calculations have shown that the latter tautomer is by ca. $0.5 \mathrm{~kJ} \mathrm{~mol}^{-1}$ more stable than the former, with the energy barrier between the two forms of ca. $10 \mathrm{~kJ} \mathrm{~mol}^{-1}$ (Figure 9, Figures S24-S26 in SI).

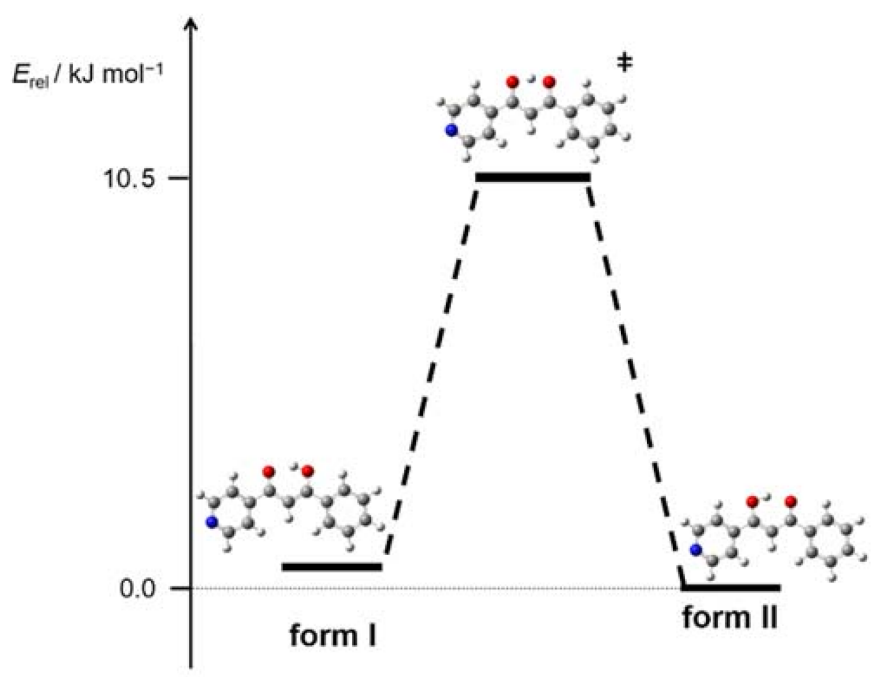

Figure 9. The relative energy of $\mathbf{b} 4 \mathrm{pm}$ form I, form II and transition structure.

In order to determine which tautomer was present in which cocrystal, it was necessary to unequivocally determine the positions of the hydrogen atoms within the intramolecular $\mathrm{O}-\mathrm{H} \cdots \mathrm{O}$ hydrogen bond. This was achieved by a combination of two parameters: the position of the corresponding maximum of electron density on a residual density plot of the diketo group (Figure 10) and the relative lengths of the two $\mathrm{C}-\mathrm{O}$ bonds (Figure 11). The combined approach is necessary as the positions of hydrogen atoms cannot always be unequivocally determined from the electron density maps obtained by X-ray diffraction due to the weakness of radiation scattering on hydrogen atoms. The correct hydrogen placement can be particularly difficult when the crystal quality is poor, as this leads to 
uneven difference maps in which the hydrogen atoms may be entirely "lost." Indeed, only in (b4pm)(ipfb), (b4pm)(12tfib) and (b4pm)(135tfib), the hydrogen atom could be located from the difference map (Figure 10a,b,f). In all three structures, the hydrogen atom is clearly positioned closer to the pyridyl oxygen atom, indicating that the tautomer II was present.

a)

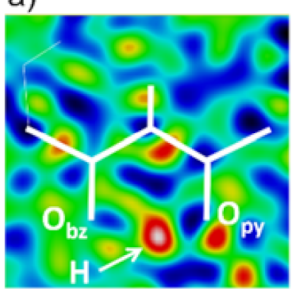

e)

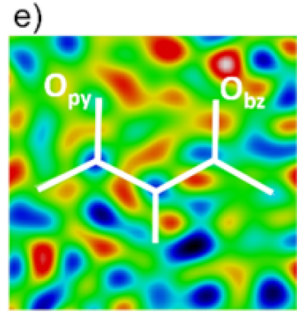

b)

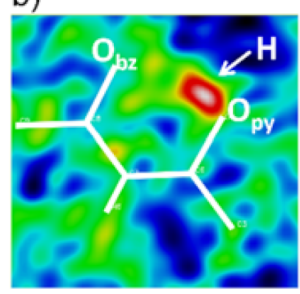

f)

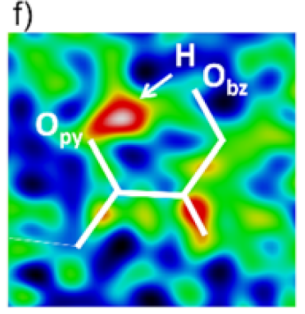

c)

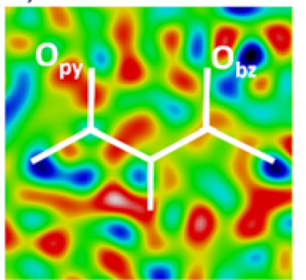

g) d)

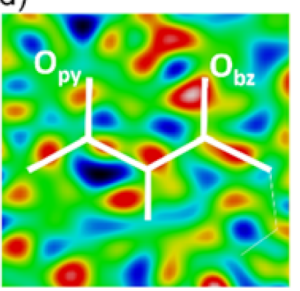

Figure 10. Electron density maps in the plane of the diketo group of (a) (b4pm)(ipfb); (b) (b4pm)(12tfib); (c-e) three independent molecules of b4pm in (b4pm)(13tfib): (f) (b4pm)(135tfib); (g) (b4pm)(14tfib).

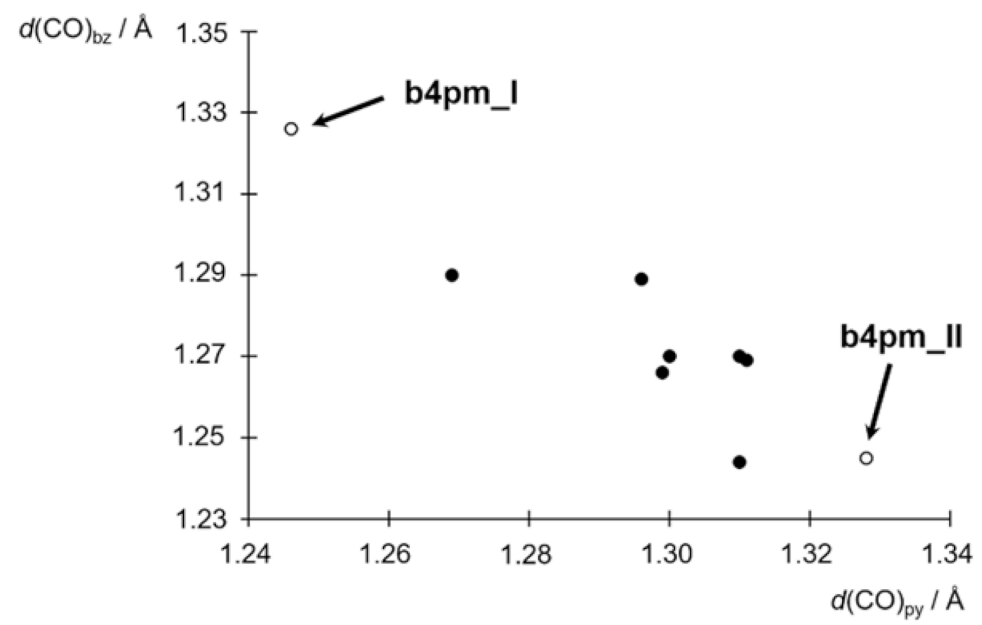

Figure 11. The interrelation between $\mathrm{CO}$ bond lengths in $\mathbf{b} 4 \mathbf{p m}$ molecule; black circles-cocrystals, white circles-optimized geometries.

For the determination of the tautomer(s) present in (b4pm)(13tfib) and (b4pm) 2 (14tfib), it was necessary to rely solely on the $\mathrm{C}-\mathrm{O}$ bond lengths. The protonated oxygen atom (technically a hydroxyl group) should be bonded to the carbon atom with a longer $\mathrm{C}-\mathrm{O}$ bond than the non-protonated (carbonyl) oxygen atom. However, due to the quasi-aromatic nature of the central keto-enol group of the molecule, both bond lengths are always somewhere between the two extremes, the isolated hydroxyl and carbonyl. Still, there is generally a measurable difference between the two $\mathrm{C}-\mathrm{O}$ bond lengths, the $\mathrm{C}-\mathrm{OH}$ bond being ca. $0.08 \AA$ longer. This is borne out by the optimized structures of the two tautomers of b4pm in vacuo, which show the difference in $\mathrm{C}-\mathrm{OH}$ and $\mathrm{C}=\mathrm{O}$ bond lengths to be $0.080 \AA$ in form I and $0.083 \AA$ in form II.

In the structures of the $\mathbf{b} 4 \mathbf{p m}$ cocrystals, for which the hydrogen atom was located from the electron difference map, the $\mathrm{C}-\mathrm{O}$ bond lengths are generally in accord with the positioning of the hydrogen atom. In all three cases, the pyridyl C-O bond is longer than 
the benzoyl $\mathrm{C}-\mathrm{O}$ bond, which is in line with the positioning of the hydrogen atom on the pyridyl oxygen, as seen in the electron difference map, indicating the presence of form II. However, the difference of bond lengths $(d(\mathrm{C}-\mathrm{O})$ pyridyl $-d(\mathrm{C}-\mathrm{O})$ benzoyl $)$ is somewhat less than in optimised structures of the tautomers: ca. $0.30 \AA$ in $(\mathbf{b} 4 \mathbf{p m})(\mathbf{i p f b}), 0.42 \AA$ in $(\mathbf{b} 4 \mathbf{p m})(\mathbf{1 2 t f i b})$ and $0.34 \AA$ in (b4pm)(135tfib). Similarly, in (b4pm) ${ }_{2}(\mathbf{1 4 t f i b})$, although the hydrogen atom could not be located from the electron difference map, the pyridyl C-O bond was found to be longer than the benzoyl $\mathrm{C}-\mathrm{O}$ bond, indicating the molecule is in the tautomeric form II. However, here again, the $d(\mathrm{C}-\mathrm{O})_{\text {pyridyl }}-d(\mathrm{C}-\mathrm{O})$ benzoyl $=0.30 \AA$ was substantially less than that in the optimized molecule of form II ( $0.083 \AA$ ). In (b4pm)(13tfib), the situation was more complex - of the three molecules independent by symmetry, one was clearly in form II $\left(d(\mathrm{C}-\mathrm{O})_{\text {pyridyl }}-d(\mathrm{C}-\mathrm{O})_{\text {benzoyl }}=0.068 \AA\right)$, while the remaining two $\left(d(\mathrm{C}-\mathrm{O})_{\text {pyridyl }}-d(\mathrm{C}-\mathrm{O})_{\text {benzoyl }}\right)$ differences were found to be close to zero $(0.01 \AA$ and $-0.02 \AA$ ), making it impossible to clearly determine which tautomer was present.

The described distribution of $\mathrm{C}-\mathrm{O}$ bond lengths in all the molecules in all the cocrystals, as well as those of the optimized structures of tautomers I and II, are given in Figure 11. It can be noticed that the data points representing the molecules in the cocrystals are positioned around a line connecting the data points corresponding to the optimized structures of the tautomers, with the majority of the data points closer to the more stable form II. A probable explanation of this trend is that the molecules in crystal structures generally do not represent pure tautomers but rather an equilibrium mixture of both forms I and II. Based on this, we can provide a rough estimate of the relative amounts of each tautomer present in each of the cases. As the determined crystal structure represents a time and space average of all molecules in the crystal, if the crystal comprises a mixture of tautomers placed on crystallographically equivalent positions, the measured bond lengths will also be average for the two forms weighted by their molar ratios, i.e., $d_{\mathrm{obs}}=x_{\mathrm{I}} d_{\mathrm{I}}+x_{\mathrm{II}} d_{\mathrm{II}}$, where $d_{\mathrm{obs}}$ is the measured length of a given bond, $d_{\mathrm{I}}$ and $d_{\mathrm{II}}$ the lengths of the equivalent bonds in 'pure' tautomers I and II, and $x_{\mathrm{I}}$ and $x_{\mathrm{II}}$ the molar fractions of the tautomers I and II, respectively. As only two tautomers are present on equivalent positions $\left(x_{\mathrm{I}}+x_{\mathrm{II}}=1\right)$, and knowing the geometries of the tautomers in vacuo, we can estimate the molar fractions of the tautomers based on any of the measured bonds. The best choices here are the two $\mathrm{C}-\mathrm{O}$ bond lengths as their lengths experience the largest change from one tautomer to another (Tables S3 and S4 in SI). Additionally, performing the computation on two independent measurements allows an estimate of the precision of the determined molar fractions. Based on this, we can estimate that the molar fractions of tautomer II in (b4pm)(ipfb), (b4pm)(12tfib), (b4pm)(135tfib) and (b4pm)2(14tfib) are 67(2)\%, 75(6)\%, $70(6) \%$ and $68(13) \%$. Notwithstanding a rather low precision of the determined fraction of II in (b4 pm)(135tfib), it can be concluded that in all four structures, the molecules of $\mathbf{b} 4 \mathbf{p m}$ are present dominantly, although not exclusively, in form II. This would confirm the $d(\mathrm{C}-\mathrm{O})_{\text {pyridyl }}-d(\mathrm{C}-\mathrm{O})_{\text {benzoyl }}$ differences of ca $0.30 \AA-0.42 \AA$ being the result of an equilibrium mixture in which ca $67-75 \%$ molecules belong to form II. For the three molecules of b4pm in (b4pm)(13tfib), the molar fractions of tautomer II are found to be 91(13)\% (for the molecule with the largest $d(\mathrm{C}-\mathrm{O})_{\text {pyridyl }}-d(\mathrm{C}-\mathrm{O})_{\text {benzoyl }}$ difference), and $37(13) \%$ and $54(7) \%$ for the other two, which is again in line with the observed $d(\mathrm{C}-\mathrm{O})_{\text {pyridyl }}-d(\mathrm{C}-\mathrm{O})_{\text {benzoyl }}$ differences, both indicating a more closely equimolar mixture of the two tautomers.

The question we originally set out to answer was whether the presence of a halogen bond could influence the tautomeric equilibrium in cocrystals of $\beta$-diketones. Unfortunately, as there is a halogen bond with one of the oxygen atoms in only two obtained cocrystals, we are unable to provide a definite answer to it. Generally, the more stable form II was found to be dominant in all crystal structures, regardless of halogen bonding, and in

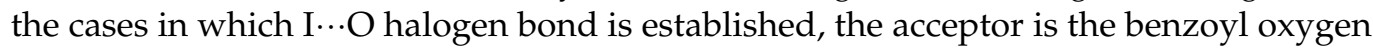
atom which corresponds to carboxyl oxygen in this tautomer. The estimated fraction of II

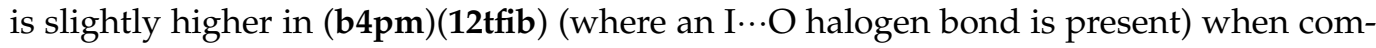
pared to (b4pm)(ipfb), (b4pm)(135tfib) and (b4pm) $)_{2}(\mathbf{1 4 t f i b})$, which might indicate some additional stabilization due to the halogen bond, but, due to a large standard deviation, it 
can hardly be regarded as statistically significant. More indicative, however, is the crystal structure of $(\mathbf{b} 4 \mathbf{p m})(\mathbf{1 3 t f i b})$, where the only molecule independent by symmetry that forms an I...O halogen bond also has the highest fraction of the tautomer II, while the other two molecules, which do not form I...O halogen bonds, exist as (equilibrium) mixtures of the two tautomers with a lower fraction of the tautomer II (ca. 40-55\%) than in the remaining structures. Therefore, it can be inferred that in this case, there has been some definite stabilization of a single tautomeric form by an I...O halogen bond.

\section{Conclusions}

The data acquired within this study indicates there is a possible effect of halogen bond in stabilizing a given tautomer: the difference in the energies of the two tautomers is sufficiently low, that halogen bond should be able to provide ample energy to stabilize the less stable tautomer, and an increase in the fraction of the tautomer in which this oxygen atom is carbonyl oxygen (and thus more negative and a better halogen bond acceptor) was found in the only two structures, where an I...O halogen bond was found. However, more definite proof of the ability of the halogen bond to affect tautomeric equilibrium would be a system in which the less stable tautomer was stabilized in the solid-state by a halogen bond. Unfortunately, in both cases where an I...O halogen bond was achieved, it was formed with the benzoyl oxygen, thus, in fact, favouring the more stable tautomer. Therefore, a definite solution to the problem of tautomer control through halogen bond still remains elusive, although the results presented herein give every hope that through further investigations, it should be possible to reach.

Supplementary Materials: The following are available online at https://www.mdpi.com/article/10 .3390 / cryst11060699/s1. Tables S1 and S2. An overview and crystallographic data of the prepared compounds; Total electron energies and Cartesian coordinates for optimised structures; Table S3. $\mathrm{CO}$ bond lengths and their differences both in optimized structures of tautomers and molecules of $\mathbf{b} 4 \mathbf{p m}$ found in halogen bonded cocrystals; Table S4. Molar fractions of form I and form II in crystal structures of halogen bonded cocrystals, calculated on basis of $\mathrm{CO}$ bond lengths shown in Table S3; Figure S1. Molecular structure of $\mathbf{b 3} \mathbf{p m}$ showing the atom-labelling scheme. Displacement ellipsoids are drawn at the 50\% probability level; Figure S2. Molecular structure of (b4pm)(12tfib) showing the atom-labelling scheme. Displacement ellipsoids are drawn at the $50 \%$ probability level; Figure S3. Molecular structure of (b4 pm)(13tfib) showing the atom-labelling scheme. Displacement ellipsoids are drawn at the $50 \%$ probability level; Figure S4. Molecular structure of $(\mathbf{b} 4 \mathbf{p m})_{2}(\mathbf{1 4 t f i b})$ showing the atom-labelling scheme. Displacement ellipsoids are drawn at the $50 \%$ probability level; Figure S5. Molecular structure of $(\mathbf{b} 4 \mathbf{p m})(\mathbf{i p f b})$ showing the atom-labelling scheme. Displacement ellipsoids are drawn at the $50 \%$ probability level; Figure S6. Molecular structure of (b4pm)(135tfib) showing the atom-labelling scheme. Displacement ellipsoids are drawn at the $50 \%$ probability level; Figure S7. Measured and calculated XRPD patterns of (b4pm)(12tfib); Figure S8. Measured and calculated XRPD patterns of (b4pm)(13tfib); Figure S9. Measured and calculated XRPD patterns of (b4pm) $)_{2}$ (14tfib); Figure S10. Measured and calculated XRPD patterns of (b4pm)(ipfb); Figure S11. Measured XRPD patterns of (b4pm)(135tfib); Figure S12. DSC thermogram of b3pm; Figure S13. DSC thermogram of b4pm; Figure S14. DSC thermogram of (b4pm)(12tfib) Figure S15.

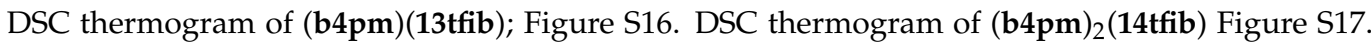
DSC thermogram of (b4pm)(ipfb); Figure S18. DSC thermogram of $(\mathbf{b} 4 \mathbf{p m})(\mathbf{1 3 5 t f i b})$; Figure S19. TG thermogram of (b4pm)(12tfib); Figure S20. TG thermogram of (b4pm)(13tfib); Figure S21. TG thermogram of $(\mathbf{b} 4 \mathbf{p m})_{2}(\mathbf{1 4 t f i b})$; Figure S22. TG thermogram of $(\mathbf{b} 4 \mathbf{p m})(\mathbf{i p f b})$; Figure S23. TG thermogram of $(\mathbf{b} 4 \mathbf{p m})(\mathbf{1 3 5 t f i b})$; Figure S24. Optimized structure of anti-b3pm; Figure S25. Optimized structure of anti-b3pm; Figure S26. Optimized structure of b4pm; Figure S27. Optimized structure of (b4pm)(ipfb)_N; Figure S28. Optimized structure of (b4pm)(ipfb)_O; Figure S29. Optimized structure of (b4pm)(ipfb)_OH. CCDC 2080725-2080730 contain crystallographic data for this paper. These data can be obtained free of charge from the Director, CCDC, 12 Union Road, Cambridge, CBZ 1EZ, UK (Fax: +44-1223-336033; email: deposit@ccdc.cam.ac.uk). 
Author Contributions: Synthesis of the parent diketones: N.B. and V.M.; cocrystal synthesis: V.M.; characterization, single-crystal and powder X-ray diffraction analysis: N.B. and V.M.; quantumchemical calculations: N.B.; Writing-original draft preparation: N.B., V.S. and D.C. All authors have read and agreed to the published version of the manuscript.

Funding: This research was supported by the Croatian Science Foundation under projects HRZZ-IP2014-09-7367 and HRZZ-IP-2019-04-1868.

Acknowledgments: This research was supported by the Croatian Science Foundation un-der projects HRZZ-IP-2014-09-7367 and HRZZ-IP-2019-04-1868.

Conflicts of Interest: The authors declare no conflict of interest.

\section{References}

1. Aakeröy, C.B.; Panikkattu, S.; Chopade, P.D.; Desper, J. Competing hydrogen-bond and halogen-bond donors in crystal engineering. CrystEngComm 2013, 15, 3125-3136. [CrossRef]

2. Aakeröy, C.B.; Spartz, C.L.; Dembowski, S.; Dwyrea, S.; Despera, J. A systematic structural study of halogen bonding versus hydrogen bonding within competitive supramolecular systems. IUCrJ 2015, 2, 498-510. [CrossRef] [PubMed]

3. Bartashevich, E.V.; Tsirelson, V.G. Interplay between non-covalent interactions in complexes and crystals with halogen bonds. Russ. Chem. Rev. 2014, 83, 1181-1203. [CrossRef]

4. Awwadi, F.F.; Taher, D.; Haddad, S.F.; Turnbull, M.M. Competition between Hydrogen and Halogen Bonding Interactions: Theoretical and Crystallographic Studies. Cryst. Growth Des. 2014, 14, 1961-1971. [CrossRef]

5. Jing, B.; Li, Q.; Li, R.; Gong, B.; Liu, Z.; Li, W.; Cheng, J.; Sun, J. Competition and cooperativity between hydrogen bond and halogen bond in HNC . . $(\mathrm{HOBr}) \mathrm{n}$ and $(\mathrm{HNC}) \mathrm{n} \cdots \mathrm{HOBr}(\mathrm{n}=1$ and 2$)$ systems. Comput. Theor. Chem. 2011, 963, 417-421. [CrossRef]

6. Bauzá, A.; Frontera, A. Competition between lone pair- $\pi$, halogen- $\pi$ and triel bonding interactions involving $\mathrm{BX} 3(\mathrm{X}=\mathrm{F}, \mathrm{Cl}, \mathrm{Br}$ and I) compounds: An ab initio study. Theor. Chem. Acc. 2017, 136, 37. [CrossRef]

7. Ji, B.; Wang, W.; Deng, D.; Zhang, Y.; Cao, L.; Zhou, L.; Ruana, C.; Li, T. Structural competition between $\pi \cdots \pi$ interactions and halogen bonds: A crystallographic study. CrystEngComm 2013, 15, 769-774. [CrossRef]

8. Nemec, V.; Lisac, K.; Bedeković, N.; Fotović, L.; Stilinović, V.; Cinčić, D. Crystal engineering strategies towards halogen-bonded metal-organic multi-component solids: Salts, cocrystals and salt cocrystals. CrystEngComm 2021, 23, 3063-3083. [CrossRef]

9. Sumi, Y.; Sasaki, K.; Tsuzuki, S.; Shibata, N. Studies of Halogen Bonding Induced by Pentafluorosulfanyl Aryl Iodides: A Potential Group of Halogen Bond Donors in a Rational Drug Design. Molecules 2019, 24, 3610-3625. [CrossRef]

10. Hutchins, K.M.; Kummer, K.A.; Groeneman, R.H.; Reinheimer, E.W.; Sinnwell, M.A.; Swensona, D.C.; MacGillivray, L.R. Thermal expansion properties of three isostructural co-crystals composed of isosteric components: Interplay between halogen and hydrogen bonds. CrystEngComm 2016, 18, 8354-8357. [CrossRef]

11. Riel, A.M.S.; Rowe, R.K.; Ho, E.N.; Carlsson, A.C.C.; Rappé, A.K.; Berryman, O.B.; Ho, P.S. Hydrogen Bond Enhanced Halogen Bonds: A Synergistic Interaction in Chemistry and Biochemistry. Acc. Chem. Res. 2019, 52, 2870-2880. [CrossRef]

12. Li, Q.; Lin, Q.; Li, W.; Cheng, J.; Gong, B.; Sun, J. Cooperativity between the Halogen Bond and the Hydrogen Bond in $\mathrm{H}_{3} \mathrm{~N} \cdots \mathrm{XY} \cdots \mathrm{HF}$ Complexes (X, Y = F, Cl, Br). ChemPhysChem 2008, 9, 2265-2269. [CrossRef]

13. Ciancaleoni, G. Cooperativity between hydrogen- and halogen bonds: The case of selenourea. Phys. Chem. Chem. Phys. 2018, 20, 8506-8514. [CrossRef]

14. Saha, S.; Sastry, G.N. Cooperative or Anticooperative: How Noncovalent Interactions Influence Each Other. J. Phys. Chem. B 2015, 119, 11121-11135. [CrossRef]

15. Stilinović, V.; Kaitner, B. Salts and Co-Crystals of Gentisic Acid with Pyridine Derivatives: The Effect of Proton Transfer on the Crystal Packing (and Vice Versa). Cryst. Growth Des. 2012, 12, 5763-5772. [CrossRef]

16. Bedeković, N.; Stilinović, V.; Piteša, T. Aromatic versus Aliphatic Carboxyl Group as a Hydrogen Bond Donor in Salts and Cocrystals of an Asymmetric Diacid and Pyridine Derivatives. Cryst. Growth. Des. 2017, 11, 5732-5743. [CrossRef]

17. Sarma, B.; Nath, N.K.; Bhogala, B.R.; Nangia, A. Synthon Competition and Cooperation in Molecular Salts of Hydroxybenzoic Acids and Aminopyridines. Cryst. Growth Des. 2009, 9, 1546-1557. [CrossRef]

18. Lemmerer, A.; Govindraju, S.; Johnston, M.; Motloung, X.; Savig, K.L. Co-crystals and molecular salts of carboxylic acid/pyridine complexes: Can calculated pKa's predict proton transfer? A case study of nine complexes. CrystEngComm 2015, 17, 3591-3595. [CrossRef]

19. Mohamed, S.; Tocher, D.A.; Vickers, M.; Karamertzanis, P.G.; Price, S.L. Salt or Cocrystal? A New Series of Crystal Structures Formed from Simple Pyridines and Carboxylic Acids. Cryst. Growth Des. 2009, 9, 2881-2889. [CrossRef]

20. Cruz-Cabeza, A.J. Acid-base crystalline complexes and the pKa rule. CrystEngComm 2012, 14, 6362-6365. [CrossRef]

21. Blagus, A.; Cinčić, D.; Friščić, T.; Kaitner, B.; Stilinović, V. Schiff bases derived from hydroxyaryl aldehydes: Molecular and crystal structure, tautomerism, quinoid effect, coordination compounds. Maced. J. Chem. Chem. Eng. 2010, 29, 117-138. [CrossRef] 
22. Rubčić, M.; Užarević, K.; Halasz, I.; Bregović, N.; Mališ, M.; Đilović, I.; Kokan, Z.; Stein, R.S.; Dinnebier, R.E.; Tomišić, V. Desmotropy, Polymorphism, and Solid-State Proton Transfer: Four Solid Forms of an Aromatic o-Hydroxy Schiff Base. Chem. Eur. J. 2012, 18, 5620-5631. [CrossRef] [PubMed]

23. Juribašić, M.; Bregović, N.; Stilinović, V.; Tomišić, V.; Cindrić, M.; Šket, P.; Plavec, J.; Rubčić, M.; Užarević, K. Supramolecular Stabilization of Metastable Tautomers in Solution and the Solid State. Chem. Eur. J. 2014, 20, 17333-17345. [CrossRef] [PubMed]

24. Užarević, K.; Rubčić, M.; Stilinović, V.; Kaitner, B.; Cindrić, M. Keto-enol tautomerism in asymmetric Schiff bases derived from p-phenylenediamine. J. Mol. Struct. 2010, 984, 232-239. [CrossRef]

25. Užarević, K.; Stilinović, V.; Rubčić, M. Supramolecular Control over Tautomerism in Organic Solids in Tautomerism: Concepts and Applications in Science and Technology; Antonov, L., Ed.; John Wiley \& Sons: Weinheim, Germany, 2016; pp. $295-328$.

26. Hadjoudis, E.; Mavridis, I.M. Photochromism and thermochromism of Schiff bases in the solid state: Structural aspects. Chem. Soc. Rev. 2004, 33, 579-588. [CrossRef]

27. Metrangolo, P.; Resnati, G. Halogen Bonding: A Paradigm in Supramolecular Chemistry. Chem. Eur. J. 2001, 7, 2511-2519. [CrossRef]

28. Cavallo, G.; Metrangolo, P.; Milani, R.; Pilati, T.; Priimagi, A.; Resnati, G.; Terraneo, G. The Halogen Bond. Chem. Rev. 2016, 116, 2478-2601. [CrossRef]

29. Stilinović, V.; Horvat, G.; Hrenar, T.; Nemec, V.; Cinčić, D. Halogen and Hydrogen Bonding between (N-Halogeno)-succinimides and Pyridine Derivatives in Solution, the Solid State and In Silico. Chem. Eur. J. 2017, 23, 5244-5257. [CrossRef]

30. Eraković, M.; Cinčić, D.; Molčanov, K.; Stilinović, V. A Crystallographic Charge Density Study of the Partial Covalent Nature of Strong N... Br Halogen Bonds. Angew. Chem. 2019, 131, 15849-15853. [CrossRef]

31. Zbačnik, M.; Vitković, M.; Vulić, V.; Nogalo, I.; Cinčić, D. Competition between Halogen Bonds in Cocrystals of Imines Derived from o-Vanillin. Cryst. Growth Des. 2016, 16, 6381-6389. [CrossRef]

32. Carletta, A.; Zbačnik, M.; Van Gysel, M.; Vitković, M.; Tumanov, N.; Stilinović, V.; Wouters, J.; Cinčić, D. Playing with Isomerism: Cocrystallization of Isomeric N-Salicylideneaminopyridines with Perfluorinated Compounds as Halogen Bond Donors and Its Impact on Photochromism. Cryst. Growth Des. 2018, 18, 6833-6842. [CrossRef]

33. Carletta, A.; Zbačnik, M.; Vitković, M.; Tumanov, N.; Stilinović, V.; Wouters, J.; Cinčić, D. Halogen-bonded cocrystals of Nsalicylidene Schiff bases and iodoperfluorinated benzenes: Hydroxyl oxygen as a halogen bond acceptor. CrystEngComm 2018, 20, 5332-5339. [CrossRef]

34. Carletta, A.; Spinelli, F.; d'Agostino, S.; Ventura, B.; Chierotti, M.R.; Gobetto, R.; Wouters, J.; Grepioni, F. Halogen-Bond Effects on the Thermo- and Photochromic Behaviour of Anil-Based Molecular Co-crystals. Chem. Eur. J. 2017, 23, 5317-5329. [CrossRef]

35. Zbačnik, M.; Pajski, M.; Stilinović, V.; Vitković, M.; Cinčić, D. The halogen bonding proclivity of the ortho-methoxy-hydroxy group in cocrystals of o-vanillin imines and diiodotetrafluoro-benzenes. CrystEngComm 2017, 19, 5576-5582. [CrossRef]

36. Chu, M.; Qiu, B.; Zhang, W.; Zhou, Z.; Yang, X.; Yan, Y.; Yao, J.; Li, Y.J.; Zhao, Y.S. Tailoring the Energy Levels and Cavity Structures toward Organic Cocrystal Microlasers. ACS Appl. Mater. Interfaces 2018, 10, 42740-42746. [CrossRef]

37. Mercier, G.M.; Robeyns, K.; Tumanov, N.; Champagne, B.; Wouters, J.; Leyssens, T. New Insights into Photochromic Properties of N-Salicylideneaniline Derivatives Using a Cocrystal Engineering Approach. Cryst. Growth Des. 2019, 19, 5544-5556. [CrossRef]

38. Koltsov, A.I. Enol-enol tautomerism in cis-keto-enols. J. Mol. Struct. 1998, 444, 1-11. [CrossRef]

39. Yoshida, Z.; Ogoshi, H.; Tokumitsu, T. Intramolecular hydrogen bond in enol form of 3-substituted-2,4-pentanedione. Tetrahedron 1970, 26, 5691-5697. [CrossRef]

40. Yoffe, S.T.; Fedin, E.I.; Petrovskii, P.V.; Kabachnik, M.I. High resolution NMR investigation of enolization of ethyl $\alpha$ alkylacetoacetates and 3-alkylacetylacetones with branched substituents. Tetrahedron Lett. 1966, 7, 2661-2668. [CrossRef]

41. Iglesias, E. Substituent effects on enol nitrosation of 1,3-diketones. Int. J. Chem. Kin. 2012, 44, 668-679. [CrossRef]

42. Iglesias, E. A new method for the nitrosation of 1,3-diketones applied to 3-ethyl-and 3-methyl pentane-2,4-dione. RSC Adv. 2013, 3, 15192-15201. [CrossRef]

43. Stilinović, V.; Portada, T.; Kaitner, B. Predominance of the triketo tautomer in acyldipivaloylmethanes in solution and the solid state. J. Mol. Struct. 2014, 1063, 123-130. [CrossRef]

44. Burdett, J.L.; Rogers, M.T. Keto-Enol Tautomerism in $\beta$-Dicarbonyls Studied by Nuclear Magnetic Resonance Spectroscopy. I. Proton Chemical Shifts and Equilibrium Constants of Pure Compounds. J. Am. Chem. Soc. 1964, 86, 2105-2109. [CrossRef]

45. Rogers, M.T.; Burdett, J.L. Keto-enol tautomerism in $\beta$-dicarbonyls studied by nuclear magnetic resonance spectroscopy: II. Solvent effects on proton chemical shifts and on equilibrium constants. Can. J. Chem. 1965, 43, 1516-1526. [CrossRef]

46. Walsh, R.B.; Padgett, C.W.; Metrangolo, P.; Resnati, G.; Hanks, T.W.; Pennington, W.T. Crystal engineering through halogen bonding: Complexes of nitrogen heterocycles with organic iodides. Cryst. Growth Des. 2001, 1, 165-175. [CrossRef]

47. Ding, X.H.; Ou, C.J.; Wang, S.; Xie, L.H.; Lin, J.Y.; Wang, J.P.; Huang, W. Co-crystallization of 1,3,5-trifluoro-2,4,6-triiodobenzene (1,3,5-TFTIB) with a variety of Lewis bases through halogen-bonding interactions. CrystEngComm 2017, 19, 5504-5521. [CrossRef]

48. Bedeković, N.; Stilinović, V.; Friščić, T.; Cinčić, D. Comparison of isomeric meta- and para-diiodotetrafluorobenzene as halogen bond donors in crystal engineering. New J. Chem. 2018, 42, 10584-10591. [CrossRef]

49. Groom, C.R.; Bruno, I.J.; Lightfoot, M.P.; Ward, S.C. The Cambridge Structural Database. Acta Cryst. 2016, B72, 171-179. [CrossRef]

50. Brown, J.J.; Brock, A.J.; Pfrunder, M.C.; Sarju, J.P.; Perry, A.Z.; Whitwood, A.C.; Bruce, D.W.; McMurtrie, J.C.; Clegg, J.K. Co-Crystallisation of 1,4-Diiodotetrafluorobenzene with Three Different Symmetric Dipyridylacetylacetone Isomers Produces Four Halogen-Bonded Architectures. Aust. J. Chem. 2017, 70, 594-600. [CrossRef] 
51. Pfrunder, M.C.; Brock, A.J.; Brown, J.J.; Grosjean, A.; Ward, J.; McMurtrie, J.C.; Clegg, J.K. A three-dimensional cubic halogenbonded network. Chem. Commun. 2018, 54, 3974-3976. [CrossRef]

52. CrysAlis CCD V171.34, Oxford Diffraction; Oxford Diffraction Ltd.: Abingdon, UK, 2003.

53. CrysAlis RED V171.34, Oxford Diffraction; Oxford Diffraction Ltd.: Abingdon, UK, 2003.

54. Sheldrick, G.M. A short history of SHELX. Acta Cryst. A 2008, 64, 112-122. [CrossRef] [PubMed]

55. Sheldrick, G.M. SHELXT-Integrated space-group and crystal-structure determination. Acta Cryst. A 2015, 71, 3-8. [CrossRef] [PubMed]

56. Farrugia, L.J. WinGX suite for small-molecule single-crystal crystallography. J. Appl. Cryst. 1999, 32, 837-838. [CrossRef]

57. Macrae, C.F.; Bruno, I.J.; Chisholm, J.A.; Edgington, P.R.; McCabe, P.; Pidcock, E.; Rodriguez-Monge, L.; Taylor, R.; van de Streek, J.; Wood, P.A. Mercury CSD 2.0-new features for the visualization and investigation of crystal structures. J. Appl. Cryst. 2008, 41, 466-470. [CrossRef]

58. Philips X'Pert Data Collector 1.3e; Philips Analytical B. V.: Almelo, The Netherlands, 2001.

59. Philips X'Pert Graphic E Identify 1.3e Philips; Analytical B. V.: Almelo, The Netherlands, 2001.

60. Philips X'Pert Plus 1.0; Philips Analytical B. V.: Almelo, The Netherlands, 1999.

61. Degen, T.; Sadki, M.; Bron, E.; König, U.; Nénert, G. The HighScore suite. Powder Diffr. 2014, 29, S13-S18. [CrossRef]

62. TARe Evaluation Software Version 15.00; Mettler-Toledo GmbH: Greifensee, Switzerland, 2016.

63. Frisch, M.J.; Trucks, G.W.; Schlegel, H.B.; Scuseria, G.E.; Robb, M.A.; Cheseman, J.R.; Scalmani, G.; Barone, V.; Petersson, G.A.; Nakatsuji, H.; et al. Gaussian 09, Revision A.02; Gaussian, Inc.: Wallingford, CT, USA, 2009.

64. Zhao, Y.; Truhlar, D.G. The M06 suite of density functionals for main group thermochemistry, thermochemical kinetics, noncovalent interactions, excited states, and transition elements: Two new functionals and systematic testing of four M06-class functionals and 12 other functionals. Theor. Chem. Acc. 2008, 120, 215-241.

65. Godbout, N.; Salahub, D.R.; Andzelm, J.; Wimmer, E. Optimization of Gaussian-type basis sets for local spin density functional calculations. Part I. Boron through neon, optimization technique and validation. Can. J. Chem. 1992, 70, 560-571. [CrossRef]

66. Sosa, C.; Andzelm, J.; Elkin, B.C.; Wimmer, E.; Dobbs, K.D.; Dixon, D.A. A local density functional study of the structure and vibrational frequencies of molecular transition-metal compounds. J. Phys. Chem. 1992, 96, 6630-6636. [CrossRef]

67. Siiskonen, A.; Priimagi, A. Benchmarking DFT methods with small basis sets for the calculation of halogen-bond strengths. J. Mol. Model. 2017, 23, 50. [CrossRef]

68. Stewart, J.J.P. Optimization of parameters for semiempirical methods. V. Modification of NDDO approximations and application to 70 elements. J. Mol. Model. 2007, 13, 1173-1213. [CrossRef]

69. Curtiss, L.A.; McGrath, M.P.; Blaudeau, J.P.; Davis, N.E.; Binning, R.C.; Radom, L. Extension of Gaussian-2 theory to molecules containing third-row atoms Ga-Kr. J. Chem. Phys. 1995, 103, 6104-6113. [CrossRef]

70. GaussView, Version 5.1; Dennington, R.; Keith, T.A.; Millam, J.M. (Eds.) Semichem Inc.: Shawnee, KS, USA, 2008.

71. Dudek, M.; Clegg, J.K.; Glasson, C.R.K.; Kelly, N.; Gloe, K.; Gloe, K.; Kelling, A.; Buschmann, H.J.; Jolliffe, K.A.; Lindoy, L.F.; et al. Interaction of Copper(II) with ditopic Pyridyl- $\beta$-diketone Ligands: Dimeric, Framework and Metallogel Structures. Cryst. Growth Des. 2011, 11, 1697-1704. [CrossRef] 